\title{
Pai misericordioso: \\ um rosto paterno e materno de Deus
}

\author{
Merciful father, \\ a paternal and maternal face of God
}

Nelson Maria Brechó da Silva*

Resumo: Este artigo apresenta o núcleo central do evangelho de Lucas: a parábola do pai misericordioso. O estudo se desenvolve em oito partes: texto, contexto, fontes e paralelos, tradições, crítica redacional, pragmática, atualização e paráfrase. Para tanto, o problema central será o fato de analisar o rosto paterno e materno de Deus presentes no pai misericordioso. Deus ama o ser humano, a tal ponto que reconduz o pecador para o caminho da paz e do amor, respeitando os seus acertos e os seus erros, fazendo com que ele procure realmente sua conversão. 0 pai, por um lado, expressa 0 rosto paterno de Deus, porque deixa o filho mais novo partir, deixando-o livre para escolher o caminho. 0 pai, por outro, revela o rosto materno de Deus, uma vez que acolhe com carinho o filho mais novo que tinha ido embora. De fato, o abraço carinhoso e os beijos que o pai concede ao seu filho mais novo demonstram a grandeza do amor de Deus, que tanto perdoa o ser humano devido ao seu amor incondicional, bem como fornece a paz para a consciência de seu filho arrependido.

Palavras-chave: Pai; Rosto; Misericórdia; Paz.

* Mestre em Filosofia e em Teologia. Doutorando em Filosofia. Professor de Filosofia e de Teologia na FAJOPA, Marília, SP. E-mail: nelsonbrecho@yahoo.com.br. 
Abstract: This article aims at showing the main idea of Luke gospel: the parable of merciful father. This study presents eight parts: text, context, sources versus comparisons, traditions, compositional criticism, pragmatic, update and paraphrasing. Thus, the focal point will be the fact of considering the paternal and maternal face of God present in the merciful Father. God loves the human being in such a way that he brings back the sinner to the path of peace and love, respecting his hits and faults making him find his conversion. At one side, the father expresses the paternal face of God because he allows his younger son to move away permitting him to be free and choose his own way. At the other side, the father reveals the maternal face of God, once he tenderly welcomes the younger son that had been away. Indeed, the affectionate embrace and kisses, which the father grants his younger son shows the greatness of God's love who not only forgives the human being due to his unconditional love, but also gives peace of mind to his repentant son.

Keywords: Father; Face; Mercy; Peace.

\section{Introdução}

Para o desenvolvimento deste nosso estudo, partiremos de uma tradução literal nossa do grego. ${ }^{2}$ Segundo Grelot, podem-se dar diversos títulos à perícope de Lc 15,11-32, a saber, "o filho pródigo, ou o filho perdido, ou o filho perdido e re-encontrado”. ${ }^{3}$ Nós preferimos o título: “A parábola do pai misericordioso", porque a figura do pai na parábola indica a presença amorosa de Deus no intuito de recuperar a dignidade de seu filho perdido. Ele ama tanto o filho que se encontra com ele quanto o filho que se encontra distante. Nesse sentido, o pai assume gestos paternais e maternais e, a partir disso,

2 Tradução nossa do grego. ALAND, B. et al. The Greek New Testament. USA: United Bible Societies, 1983, pp. 277-278.

3 Tradução nossa do francês. GRELOT, P. Le père et ses deux fils: Lc XV, 11-32. Revue Biblique 84 (1977), p. 333. 
poderemos no decorrer do artigo analisar que é possível ver nesta parábola uma "ética oblativa”, na qual o pai atua como zelador.

\section{Texto}

Vejamos o texto:

${ }^{11}$ Disse, então, um certo homem tinha dois filhos.

${ }^{12} \mathrm{E}$ disse o mais jovem deles ao pai: dá-me riqueza (patrimônio) que me corresponde. Ele (o pai), então, dividiu entre eles o sustento (bens).

${ }^{13} \mathrm{E}$ depois, não muitos dias, recolhendo tudo, o filho mais jovem partiu para uma região (país) distante e ali esbanjou (dilapidou) o seu patrimônio vivendo luxuriosamente.

${ }^{14} \mathrm{Gastando}$, então, tudo, aconteceu uma fome severa naquela região. E ele começou a (ter) necessidade.

${ }^{15} \mathrm{E}$ foi se arrimou (juntou) a um dos cidadãos daquela região. E o enviou aos seus campos para alimentar (apascentar) porcos,

${ }^{16} \mathrm{E}$ ansiava fartar-se com as algarobas que os porcos comiam. E ninguém dava a ele.

${ }^{17}$ Então, entrando em si mesmo disse: quantos diaristas (empregados) do meu pai não tem pão abundante e eu aqui pereço?

${ }^{18}$ Levantar-me-ei e me conduzirei ao meu pai e direi a ele: pai, pequei contra o céu e diante de ti.

${ }^{19}$ Não mais sou merecedor de ser chamado teu filho; faz-me como a um dos teus diaristas (empregados).

${ }^{20} \mathrm{E}$ levantando-se veio até o seu pai. E ainda longe (distante), o seu pai o viu e se comoveu e correndo abraçou-o sobre o pescoço e encheu-o de beijos.

${ }^{21}$ Disse então o filho a ele: pai, pequei contra o céu e perante (diante de) ti, não mais sou merecedor de ser chamado teu filho. ${ }^{22}$ Disse então o pai para os seus servos: depressa trazei uma veste a primeira e vesti-o e coloca um anel para mão dele e sandália para os pés.

${ }^{23} \mathrm{E}$ trazei o novilho cevado, matai-o, e comendo nos alegremos. ${ }^{24}$ Porque este meu filho estava morto e reviveu, estava perdido e foi achado. E começaram a festejar. 
${ }^{25}$ Estava então o filho mais velho no campo: e ao vindo perto da casa, ouviu música e dança.

${ }^{26} \mathrm{E}$ chamando um dos rapazinhos, perguntava que podia ser essas coisas.

${ }^{27}$ Este então disse a ele: o teu irmão veio e o teu pai matou o novilho cevado, porque salvo (são) o recuperou.

${ }^{28}$ Então enfureceu-se e não queria entrar, então o seu pai saindo o consolou, então respondendo disse ao pai: veja tantos anos te sirvo e nunca (jamais) mandamento teu transgredi e a mim nunca deste um cabrito para que com os meus amigos festeje.

${ }^{29}$ Ele porém respondeu (dizendo) para o pai dele, (eu) trabalho para ti há tantos anos, jamais desobedeci a qualquer ordem tua, e nunca me deste um novilho para eu festejar com os meus amigos. ${ }^{30}$ Mas quando este teu filho esbanjou teus bens com as prostitutas veio, mataste para ele o novilho cevado.

${ }^{31}$ Então disse ele a este: filho, tu estás sempre comigo e todas as minhas coisas são tuas.

${ }^{32}$ Festejar, pois e alegrar-se convinha (era inevitável), porque este teu irmão estava morto e reviveu e perdido foi encontrado.

\section{Contexto}

É importante, a partir disso, situar o contexto histórico de Lucas. Vemos que o evangelho foi escrito por ele mesmo, que escreveu, também, os Atos dos Apóstolos (cf. Lc 1,1-4 com At 1,1-2) e foi companheiro de Paulo (cf. Cl 4,14; Fm 24; 2 Tm 4,11). Lucas, provavelmente escreveu na mesma época que Mateus, mais especificamente depois da destruição do templo de Jerusalém (70 d.C.). Entretanto, Mateus redigiu às comunidades de judeu-cristãos; ao passo que Lucas se dirigiu às igrejas erigidas por Paulo (com Silas, Timóteo e Tito), no mundo da cultura grega ou helenista. Segundo o modelo desta cultura, Lucas redigiu uma "história”, distintamente de Mc, que compôs o resumo do anúncio, tendo a forma de uma catequese inicial.

Ademais, Lucas agrupou as tradições que a comunidade conservava acerca de Jesus: milagres, exorcismos, parábolas e outras palavras de Jesus, como também o imponente relato da Paixão. 
Difere também de Mateus, que aborda uma catequese a partir da Lei: Torá. Não sendo testemunha ocular dos fatos, Lucas investigou os testemunhos antigos e compôs um evangelho “em boa ordem' (cf. Lc 1,3), de acordo com as regras da historiografia. Ele usou como base o insigne evangelho de Marcos e a coleção de palavras de Jesus pelas quais encontramos no evangelho de Mateus.

O evangelho de Lucas é uma obra autônoma e altamente original, contendo muita coisa que não se encontram nos outros evangelhos. Assim, a história que Lucas escreve não é acadêmica e sim uma história teológica, pois organiza os dados de maneira a transmitir a imagem de Cristo (e da primeira Igreja) que somente a fé pode conceber. Lucas é, de fato, um "escritor de grande talento e uma alma delicada”. Ele faz uma teologia da misericórdia que leva em conta o amor como comprometimento pelo cuidado do outro. $\mathrm{O}$ outro comove, visto que revela a presença de Cristo como rosto do Pai Querido. Por essa razão, escolhemos como título "A parábola do pai misericordioso".

Além disso, a obra lucana deve ser vista em conjunto com a segunda parte de sua obra, os Atos dos Apóstolos. O evangelista situa o evangelho dentro da "história da salvação", que abrange três épocas: o tempo da promessa (o Primeiro Testamento), o tempo do cumprimento (Jesus) e o tempo final, que é o tempo do anúncio pela Igreja, que está descrito nos Atos dos Apóstolos (cf. At 1-2).

A perícope que estudaremos neste presente artigo, localiza-se no capítulo 15 e, é sem dúvida, o relato lucano mais relevante a propósito da misericórdia de Deus. ${ }^{5}$ Por meio das três parábolas conhecidas, o evangelista reflete, segundo óticas diferentes, sobre a realidade do pecado e a solicitude amorosa de Deus para com o pecador. A parábola do pai amoroso apresenta o ponto ápice do

4 BÍBLIA DE JERUSALÉM. São Paulo: Paulus, 1995, p. 1834.

5 CASAlEgnO, A. Lucas. A caminho com Jesus missionário. São Paulo: Loyola, 2003, pp. 210-214. 
capítulo. Nela, o pai tem o papel mais importante. Os dois filhos apresentados de forma antitética são, de certo modo, secundários. No contexto anterior o relato se refere à parábola da mulher zelosa em que notamos a alegria dela quando encontra a moeda perdida. No relato posterior, temos o administrador infiel que é mandado ir embora pelo patrão rico.

\section{Fontes e paralelos}

Mediante o trabalho redacional de Lucas, constatamos as fontes e paralelos. O seu escrito mostra, por um lado, proximidade com textos do Segundo Testamento como João (cf. Jo 17,10 com Lc 15,31) e Efésios (cf. Ef 2,1.5; 5,14 com Lc 15,24). Por outro, do Primeiro Testamento: profetas Isaías e Jeremias (cf. Is 49, 14-16. 55,7 e Jr 31,20; com Lc 15,19-20); Tobias (cf. Tb 11,9 com Lc 15,13 e 11,19 com Lc 15,19-20); Zacarias (cf. Zc 3,4 com Lc 15,21); Salmo (cf. Sl 51,4 com Lc 15, 18) e Provérbios (cf. Pv 29,3 com Lc 15,13).

\section{Tradições judaicas e cristãs}

Existem vários dados na perícope lucana que se referem à tradição judaica. A imagem do filho mais velho, que alude ao presbítero, ancião e líder, revela, primeiro, a atitude dos fariseus e escribas, pois estes se consideram "justos” e não transgridem nenhum preceito da Lei. Segundo, o fato de ter matado um novilho gordo, sendo que ele, que foi sempre justo, nunca tinha recebido tal recompensa. Terceiro, tinha uma visão de um pai distante, no qual tinha que se cumprir o que ele mandava: ética do dever. Tal experiência se assemelha a um “juiz”, ${ }^{6}$ de forma que se vê apenas uma visão paterna, típico da tradição judaica, em que o pai é o chefe da família, bet'av (casa do pai). Quarto, o novilho gordo só era reservado para grandes festas.

6 BARREIRO, A. A parábola do pai misericordioso. São Paulo: Loyola, 1998, p. 100. 
Além disso, há diversos elementos que são da tradição cristã. Quanto ao filho mais novo, primeiro, embora tendo esbanjado todos os seus bens, retorna para casa. Segundo, o pai se comove ao ver o filho, pois o seu amor supera os limites de um ser humano, revelando uma visão materna de Deus. Percebemos no momento no qual o pai o abraça, sente compaixão e cobre o filho de beijos. Para Kasper, "a misericórdia do pai ultrapassa toda a medida esperada. Não se orienta pela justa distribuição de bens materiais, mas sim pela dignidade filial. É esse o critério do amor”?

Terceiro, notamos uma “ética oblativa”, porque, por um lado, a atitude do pai demonstra ser amoroso e próximo do seu filho mais novo, mesmo diante da rebeldia que ele o provocara ao afastar de seu irmão mais velho. Ele vê o amor de Deus presente nos dois filhos como oferta dada por Deus e que ele pode ofertar com a correspondência a esse amor divino. Por outro lado, o pai restaura a dignidade do filho dando túnica, anel, sandália e um novilho gordo para festejar. Percebe nos olhos do filho, o arrependimento e visualiza uma vida nova no filho. Em relação ao filho mais velho, o pai demonstra uma consciência tranquila e pacífica, porque ele diz para ele que tudo o que é dele é dos dois filhos também.

\section{Crítica redacional}

A crítica redacional nos leva a refletir que o evangelho de Lucas não é escrito isoladamente da literatura do Primeiro Testamento. Dessa forma, o Segundo Testamento cumpre aquilo que está dito no Primeiro. Disso decorre que é imprescindível para um exegeta o fato de observar as palavras minuciosamente, observando as conexões com outros textos bíblicos.

Em relação à parábola do pai misericordioso, destacamos três grandes blocos: no primeiro, o filho mais novo (cf. 11,11-20). Nessa

7 KASPER, W. A misericórdia. Condição fundamental do Evangelho e chave da vida cristã. São Paulo: Loyola, 2015, pp. 92. 
passagem, vemos o afastamento do pai e a perdição do filho (cf. v. 11-16). O filho abandona a casa do pai. O pai, por sua vez, respeita a liberdade do filho. Nisso, o filho faz a experiência da perdição e a busca da felicidade onde não pode ser encontrada. No segundo, notamos a conversão e o regresso do filho perdido (cf. v. 17-19) em que ocorre o processo de conversão e a decisão do filho em voltar para junto do pai.

No terceiro bloco, o filho mais velho (cf. v. 25-32). O comportamento do filho mais velho (cf. v. 25-28) revela a surpresa, a raiva e o fechamento em si mesmo. O pai saiu para suplicar-lhe. Percebe-se a crítica do filho mais velho ao comportamento do pai (cf. v. 29-30). Um discurso que transpira autossuficiência, ressentimento e, inclusive, inveja. Disso decorre a observância farisaica dos mandamentos, de tal forma que o filho mais velho somente serve, mas não ama. 0 pai demonstra a figura de um Deus novo e até mesmo escandaloso para os defensores da velha ordem farisaica. Com efeito, a decisão de acolher ou rejeitar o amor gratuito de Deus está nas mãos do filho mais velho (cf. v. 21-32).

Aliás, no terceiro bloco (cf. v. 20-25), observa-se a figura do pai, que é central na perícope. Segundo Marshall, "a figura central é o pai [...] a descrição da parábola como ‘A espera do Pai’”. 8 A revelação de Deus como nosso Abbá. O pai sai para ir ao encontro do filho mais novo (cf. v. 20). Depois, destaca-se a confissão do filho e a festa que o pai manda preparar (cf. v. 21-24). O pai acolhe em silêncio a confissão do filho, pois o amor de Deus perdoa e devolve ao filho a dignidade perdida, em outras palavras, a "ética oblativa”, que consiste em dar a paz ao coração enfermo e envolvê-lo na misericórdia, que é remédio para curar os pecados. A atitude do pai recorda a seguinte passagem do profeta Isaías: “[...] eram as nossas

Tradução nossa do inglês. MARSHALL, I. H. The gospel of Luke. A commentary on the greek text. Exeter: The Paternoster Press, 1978, p. 604. (The New International Greek Testament Commentary). 
enfermidades que (o servo sofredor) levava sobre si, as nossas dores que ele carregava" (Is 53,4). O pai sente a dor de seu filho e, por isso, acolhe-o silenciosamente, de maneira a contagiar com o seu amor o coração amargurado do filho.

O pai manda fazer uma grande festa, como convite à alegria a ser partilhada, matando um novilho gordo. 0 pai volta a sair para ir ao encontro do filho mais velho (cf. v. 28.31.32). Nesse sentido, vê-se a reação do pai ao discurso rancoroso e agressivo do filho mais velho. Essa reação supera as imagens de um Deus distante, visto que Ele ama a todos os seus filhos com um amor singular e total. Deus nos amou primeiro e para sempre. Jesus não humilha os escribas e fariseus. Apenas tenta convencê-los de que devem abandonar sua rigidez, isto é, a “ética do dever”, que consiste em agir por obrigação e não por amor.

A parábola do pai misericordioso conduz o ouvinte a confrontar-se com a verdade de sua situação existencial e a tomar decisões novas com liberdade, tendo como exemplo a atitude do pai com seus filhos. ${ }^{9}$ E mais: o protagonista principal é Deus. Segundo Grelot, para o filho mais novo "a conversão do desejo é realizada; para o filho mais velho, ela permanece a questão essencial de sua vida" ${ }^{10}$ Vale mencionar que o tema da misericórdia está evidente em outras passagens do evangelho de Lucas, tais como: na parábola da ovelha perdida (cf. Lc 15,1-7) e na moeda perdida (cf. Lc 15,8-10).

\section{Pragmática}

A pragmática de Lc 15,11-32 permite pontuar que a intenção de Lucas é a de mostrar como devem comportar-se, agir e reagir os discípulos de Jesus com relação aos perdidos, seja qual for sua forma de perdição. Este é um dado fundamental da "ética oblativa”. De acordo com Fabris e Maggioni, a parábola quer ser um convite

9 BARREIRO, A. A parábola do pai misericordioso, pp. 22-37.

10 Tradução nossa do francês. GRELOT, P. Le père et ses deux fils: Lc XV, 11-32, p. 347. 
a descobrir na imagem do pai o amor e a bondade acolhedora de Deus, a se deixar envolver pela dinâmica deste amor, a participar na sua alegria. Agora, os homens são chamados a tomar parte na alegria de Deus, abrindo-se a um amor que tem o mesmo horizonte daquele de Deus, que é o horizonte de amar sem medidas. ${ }^{11} \mathrm{Com}$ efeito, o final da história do filho mais novo é um novo começo; uma grande festa de paz e misericórdia, que tem início, mas não tem fim. A “ética oblativa” impele a amar sem medidas e a ajudar o próximo na recuperação de sua dignidade.

O texto convida o leitor a observar que Deus é verdadeiramente Pai querido de todos os seres humanos. Aliás, no relato, temos diversas personagens curiosas: o filho mais novo como aquele que é excluído pela sociedade, o filho mais velho representando os fariseus e o pai, que demonstra a atitude materna e paterna de Deus. Deus é mistério de amor que perdoa e reintegra, que valoriza a liberdade do ser humano, que reconduz o pecador para o caminho certo, respeitando as suas escolhas e seus erros, fazendo com que ele procure sua conversão.

É acolhendo os pecadores, que Jesus se torna, na história, um sinal concreto, pois Ele é o "acontecimento fundante" da fé, em outras palavras, a nossa "pedra preciosa". A relação entre o pai e o filho desperta uma visão materna de Deus, de tal maneira que o nosso relacionamento com Deus compreende a dimensão paterna e materna.

\section{Atualização}

Se pensarmos na atualização de Lc 15,11-32, percebemos que a dimensão comunitária está cada vez mais descartada, devido ao excesso de consumismo, que revela uma “ética diluída”, em que as palavras e os gestos perdem o seu encanto. As pessoas, na maioria

11 FABRIS, R.; MAGGIONI, B. Os evangelhos. São Paulo: Loyola, 1992, pp. 161-163. (Bíblica Loyola, 2). 
das vezes, procuram um relacionamento com interesse, vendo no outro um meio para explorá-lo. Mas, mesmo assim, não podemos nos desanimar e tampouco fazer o bem para o próximo simplesmente para cumprir o dever. Trata-se, desse modo, de ofertar para Deus aquilo que recebemos Dele: a vida. Eis os elementos essenciais de uma "ética oblativa".

Precisamos resgatar a dimensão do pai misericordioso para sermos um sinal de luz diante da escuridão do consumismo. A postura cristã necessita de um olhar diferente para corresponder ao amor de Deus, perante a oferta de nossa vida e das pessoas que amamos para o Pai, nosso criador. O pai misericordioso, de acordo com a reflexão de Éplattenier, "não privilegia o filho mais velho. $\mathrm{O}$ filho mais velho é um retrato polêmico, mas não caricatural, dos fariseus adversários de Jesus, porque eles murmuram contra a sua prática de comensalidade com os pecadores”. ${ }^{2}$

Como ser cristão que ame da mesma forma que o Pai querido? Primeiro, é necessário o encontro com Jesus e, em seguida, fazer a eleição de fazer parte da comunidade cristã. Depois, surge o enamoramento por meio do acompanhamento e do olhar voltado a Jesus. Disso decorrem duas afirmações: reconhecermos que tudo é Dele e que, com Ele, podemos ser mais do que nós somos. No nosso interior se encontram muitas virtudes que ainda não nasceram. Contudo, ao refletir sobre o pecado se pode analisar o contrário dele que corresponde à virtude. Para tanto, é indispensável sentir-se como pecador agraciado pela misericórdia do nosso Pai Querido.

\section{Paráfrase}

É possível parafrasear a parábola do seguinte modo: assim como o pai, que se comove frente ao filho mais novo, também, nós somos convidados a nos comover diante das situações injustas em

12 L'ÉPlATtENIER, C. Leitura do evangelho de Lucas. São Paulo: Paulinas, 1993, p. 145. 
que estamos vivendo. O pai representa a atitude de Jesus Cristo e da Igreja que se ocupa dos homens que se encontram esquecidos e perdidos. Conforme Pikaza, a defesa do perdão e a atitude de Cristo ficam claras na atitude exemplar do pai. ${ }^{13}$

A fé implica ação, de modo que estaremos testemunhando aquilo que cremos. Precisamos olhar nos olhos das pessoas, pois estas, por sua vez, revelam aquilo que nós somos. Com isso, através do diálogo e, sobretudo, do trabalho missionário, nós vamos cativando as pessoas, mostrando para elas o verdadeiro sentido do amor, que aquece nosso corpo e a nossa alma com a paz e a misericórdia divina.

\section{Conclusão}

Enfim, a análise lucana sobre a misericórdia nos ajuda a apresentar para as pessoas um Deus com rosto paterno, que nos concede o mundo e a nossa vida e um rosto materno, que se manifesta no meio de nós por intermédio do Filho para nos salvar. Além disso, a plenitude desse rosto paterno e materno está na ação do Espírito Santo, que nos santifica, dando-nos uma vida nova e a paz. Por esse motivo, vale lembrar o célebre pensamento lucano: "sede misericordiosos como vosso Pai é misericordioso” (Lc 6,36).

Amar a Jesus é observar a sua intimidade de filho com o nosso Pai Querido. Utilizamos a expressão “Pai Querido” para “Deus Papaizinho” para que possamos meditar sobre o maior presente que Ele deu-nos: a dignidade de sermos chamados filhos e filhas de Deus. Será que temos consciência de tê-lo como nosso "Pai Querido"? Dessa maneira, vale a pena citar o pensamento da carta joanina: “(Jesus) deu a vida por nós. E nós também devemos dar a nossa vida pelos irmãos” (1Jo 3,16). A “ética oblativa” pode ser fundamentada nesta passagem bíblica, porque no exercício de amar e de servir o próximo é que podemos ganhar a vida com um novo olhar que seja, de fato,

13 PIKAZA, J. A teologia de Lucas. São Paulo: Paulinas, 1978, pp. 95-100. 
admirador diante da beleza do mundo que nos rodeia e nos prepara para a vida eterna no encontro definitivo com o "Pai Querido".

\section{Bibliografia}

ALAND, B. ET AL. The Greek New Testament. USA: United Bible Societies, 1983, pp. 277-278.

BARREIRO, A. A parábola do pai misericordioso. São Paulo: Loyola, 1998.

BÍBLIA DE JERUSALÉM. São Paulo: Paulus, 1995, pp. 1959-1960.

CASALEGNO, A. Lucas. A caminho com Jesus missionário. São Paulo: Loyola, 2003, pp. 307-318.

FABRIS, R.; MAGGIONI, B. Os evangelhos. São Paulo: Loyola, 1992, pp. 161-163. (Bíblica Loyola, 2).

GRELOT, P. Le père et ses deux fils: Lc XV, 11-32. Revue Biblique 84 (1977), pp. 321-348; 538-565.

KASPER, W. A misericórdia. Condição fundamental do Evangelho e chave da vida cristã. São Paulo: Loyola, 2015, pp. 90-100.

L'ÉPLATTENIER, C. Leitura do evangelho de Lucas. São Paulo: Paulinas, 1993, pp. 141-147.

MARSHALL, I. H. The gospel of Luke. A commentary on the greek text. Exeter: The Paternoster Press, 1978, pp. 604-613. (The New International Greek Testament Commentary).

PIKAZA, J. A teologia de Lucas. São Paulo: Paulinas, 1978, pp. 95-100. 